\title{
Behavioral economics and public choice: introduction to a special issue
}

\author{
Gregory DeAngelo ${ }^{1} \cdot$ Bryan C. McCannon $^{2}$
}

Published online: 10 October 2021

(C) The Author(s), under exclusive licence to Springer Science+Business Media, LLC, part of Springer Nature 2021

\begin{abstract}
We provide an introduction to a special issue on behavioral economics and public choice.
\end{abstract}

Keywords Behavioral Economics · Nudge $\cdot$ Pro-social preferences $\cdot$ Public Choice $\cdot$ Rationality $\cdot$ Social norms

JEL Classification D9 $\cdot$ H0

\section{Introduction}

A fundamental presumption of public choice scholarship is methodological individualism. ${ }^{1}$ That presumption requires that social, political, and economic phenomena must be explained by showing how they result from individual action (Heath, 2020). It necessitates analyses of what motivates individuals when they make decisions and assessing how it is that they evaluate the opportunities laid before them.

Broadly, behavioral economics is a positive science that seeks to establish empirically the processes through which decisions are made. The field probes the edges of the canonical neoclassical price-theory models by asking whether real humans behave as they are presumed to behave in our standard conceptual frameworks. In recent years, behavioral economics has made its way into the mainstream of economics. ${ }^{2}$ To illustrate, Fig. 1 depicts the number of papers in journals published by the American Economic Association under the JEL classification code D9-Micro-Based Behavioral Economics ${ }^{3}$ - over the past few decades.

\footnotetext{
1 Behavioral symmetry and politics as exchange are the other two fundamental presumptions of public choice research.

${ }^{2}$ Indeed, Richard Thaler was awarded the 2017 Nobel prize in economics for his contributions to behavioral economics.

3 We combine D9 with JEL code E7 (Macro-Based Behavioral Economics), but only three papers have listed this subfield in the past 20 years.
}

Bryan C. McCannon

bryan.c.mccannon@gmail.com

1 Claremont Graduate University, Claremont, USA

2 West Virginia University, Morgantown, USA 


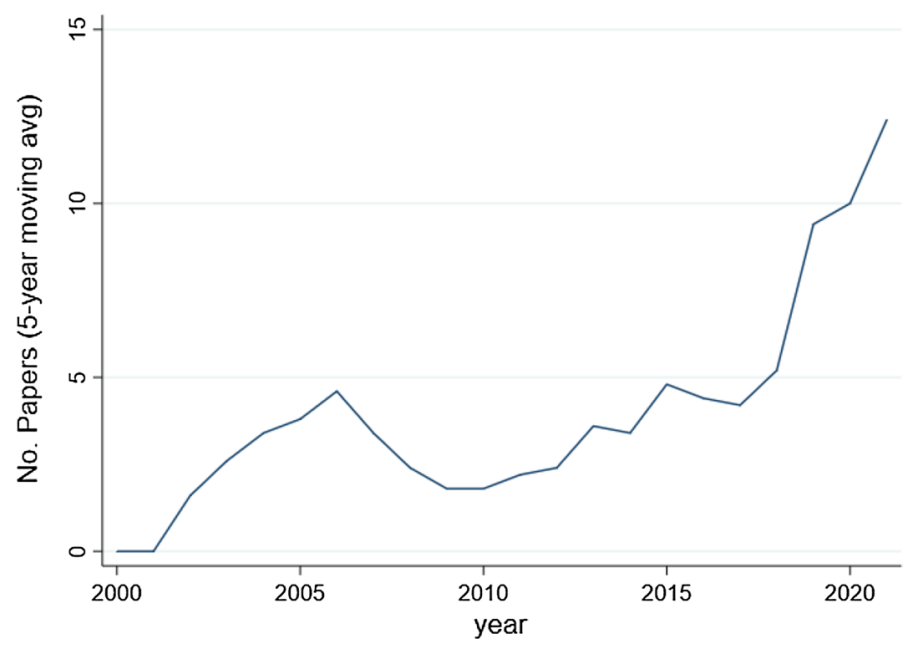

Fig. 1 Behavioral economics in AEA publications. Notes: Only papers with a listed JEL code of either D9 or E7 are counted. All papers from the American Economic Review, American Economic Review: Insights, American Economic Journal: Applied Economics, American Economic Journal: Economic Policy, American Economic Journal: Microeconomics, and American Economic Journal: Macroeconomics are tracked over time

While Fig. 1 examines only a subset of publications, it is indicative of a general rise in the use of behaviorists' insights in modern research. In this special issue we pull together research by a number of prominent scholars in behavioral economics, public choice, or both, to comment on the former's role in the latter.

\section{What is behavioral economics?}

Different scholars seem to have adopted different definitions of what constitutes research in the field of behavioral economics. Defined as broadly as possible, behavioral economics seeks to challenge the canonical assumptions of the bedrock economic model of rational individual decision making. It is the positive science that tests assumptions in standard microeconomic models of consumer choice.

The classical framework presumes that individuals engage in utility maximizing behavior. People have preferences that are complete, transitive, and stable over time. Sunk costs are ignored but opportunity costs are not. For decision making over time, people discount the future exponentially. Individuals maximize expected utility when choosing under conditions of uncertainty. Both types of decisions are made without the influence of reference points, endowment effects, or loss aversion. Choices are made with total recall of the consequences of past actions and the ability to anticipate future choices fully. When new information arrives, beliefs are updated according to Bayes Rule.

The foregoing just begins a list of the features of the mainstream framework that behavioral economics challenges. Researchers engage those assumptions using laboratory, field, and observational data to both question their validity and formulate alternative frameworks for human choice (Thaler, 2018). Consequently, behavioral economics research investigates 
four broad lines of inquiry, built on the assumptions of the canonical framework. The field's challenges include:

(1) Intertemporal decision making: whether individuals adopt exponential discounting to make unbiased forecasts of future payoffs,

(2) Decision making under uncertainty: whether people are expected utility maximizers and update beliefs as new information comes in according to Bayes' Rule,

(3) Rationality: whether humans truly maximize an objective function or rely on heuristics to make choices,

(4) Self-centered preferences: whether consumption-focused, expected-wealth-maximizing behavior is an accurate depiction of individual preferences.

No single collection of published papers can tackle all of those dimensions. While, admittedly, time preferences and risk preferences have numerous important applications in economics, the sociopolitical aspect of public choice scholarship moves the second two items on our list to the forefront of interest.

\section{Pro-social preferences}

Johanna Mollerstrom provides an archetypal investigation of pro-social preferences in "Favoritism and Cooperation". Her laboratory experiment involves a two-stage interaction. In the first stage, subjects engage in a task solving math problems to earn money. In the second stage, subjects who solved the most problems correctly are selected to play a second game offering them the opportunity to earn more money. The second stage is a series of public goods games, which commonly are played as ways of assessing pro-social preferences. Two treatments are considered. In one "fairness" treatment, each subject is given the same opportunity to be selected to play the second game, while in the second "favoritism" treatment a subset of subjects is guaranteed to move to the second stage regardless of the effort they put forth in the first stage. In her experiment, the behavior of those in the favoritism treatment exhibit much less pro-social behavior than subjects in the equal treatment sessions.

The connection to public choice is obvious. A central focus of the field is that, consistent with Olson's (1965) logic of collective action, well-organized special-interest groups will be more successful in capturing gains from public policy processes (concentrated benefits). Those gains often come at the expense of less well-organized groups (dispersed costs). Standard models rely, though, on public actors to engage in other-regarding behavior. For example, we ask judges to exert time and effort to make good rulings even though the judges themselves are unlikely to be affected personally by the quality of their rulings. Both that example and the broad point that public actors are asked to contribute to the provision of public goods voluntarily, mean that public institutions rely heavily on pro-social behavior, as articulated by Tullock (1971). Mollerstrom's experimental results imply, inter alia, that favoritism towards one group can foster antisocial preferences towards other groups.

Similarly, Anabela Botelho, Glenn Harrison, Ligia Pinto, Don Ross and Elisabet Rutström explore voluntary contributions in public goods games further in "Endogenous Choice of Institutional Punishment Mechanisms to Promote Social Cooperation". In that contribution, the authors investigate the imposition of costly sanctions to promote 
pro-social behavior, thus connecting closely to regulatory actions that, rather than relying solely on private motivations or positive inducements (i.e., "carrots"), public agencies resort to threats (i.e., "sticks") to coerce contributions. Past research has shown that sanctions effectively promote contributions to public goods even when the sanctions are costly to impose (Fehr \& Gächter, 2000, 2002; Ostrom et al., 1992).

Botello et al. move the literature a step further by adopting an endogenous institutions framework. Their experiment offers multiple versions of a game and subjects are permitted to choose one of the versions to play. The methodology allows the experimental researcher to let subjects express opinions about their preferred institutional arrangement. A previous example of such a study can be found in Isaac and Norton (2013), who consider crowding out by allowing subjects to choose whether to contribute voluntarily to public goods or rely on a mandatory tax-financing scheme.

In Botello et al.'s experiment, after playing both games, subjects voted for the version to be played in a final round. The result is stark-almost $78 \%$ of the subjects vote for playing the game without punishments for failing to contribute. As they conclude eloquently, "a distinction is required between the principles that guide the choice of institutions and the principles that apply to actions guided by institutions", a sharp difference emphasized by Buchanan and Tullock (1962).

An important application of pro-social behavior relates to how a society treats its less fortunate members. Mazen Hassan, Sarah Mansour, Stefan Voigt and May Gadallah conduct a lab-in-the-field experiment. In "When Syria was in Egypt's Land", Hassan et al. set up a series of experiments with Egyptians and Syrian refugees in Egypt. Using games common in experimental economics, the authors report that Egyptians treat the Syrian refugees more favorably than they treat their fellow Egyptians, while Syrian's behavior is unrelated to the identify of their playing partners.

The implication is that the preferences underlying foreign aid policies depend on the circumstances surrounding aid recipients. Individuals forced to flee their homeland owing to civil war are a sympathetic group. Nationals are willing to support public institutions that assist the less fortunate. The conclusion is consistent with prior work showing that voters' willingness to agree to redistributive programs depends on whether wealth is earned or unearned (DeAngelo et al., 2020; Lefgren et al., 2016). Taken together, the three papers supply examples of pro-social preferences influencing behavior within public institutions.

\section{Less-than-fully-rational decision making}

Voting over pro-social outcomes is studied explicitly by the late Rebecca Morton, Kai Ou and Xiangdong Quin in "Analytical Thinking, Prosocial Voting and Intergroup Competition". Morton et al. conduct a lab-in-the-field experiment in China where subjects vote whether or not to transfer a portion of their wealth to another subject. If the majority of the three-person group votes to transfer, then wealth is redistributed.

To that pro-social choice, the authors add a contrast between in-group and out-group giving. The experiment took place in Ningxia, China. Han Chinese comprise the local population's majority, alongside a minority of Chinese Muslims. Treatments vary by whether the recipient matches the group's ethnicity. What is unique about their experiment is that they introduce less-than-fully-rational decision making. They build on the framework of Kahneman (2011), wherein System-1 thinking is an automatic and fast decision-making 
process, while System-2 is deliberative and engages subjects' analytical thinking. The authors prime System- 2 by posing a series of analytical thinking exercises.

Morton et al.'s analysis shows that while analytical thinking has only a negligible effect on voting for redistribution to those in the in-group, it reduces pro-sociality towards the out-group substantially. Therefore, voting on redistributive policies is not just about preferences; it also has a cognitive dimension.

Roger Congleton in "Behavioral Economics and the Virginia School of Political Economy" provides interesting comparisons and contrasts between behavioral economics and public choice. He argues that the subjectivist strand of the latter connects nicely to the psychological strand of the former. Subjectivists, Congleton states, "argue that choices reflect understandings of circumstances and interests that differ widely among individuals." Consequently, utility-maximizing models do not necessarily characterize markets or politics fully. Congleton thus sees aspects of public choice reasoning (e.g., rationally ignorant voters; see below) as being much like the less-than-fully-rational decision making studied by behavioral economists who also look beyond the utility-maximization framework to understand choices.

Like mental processes, inattention is another area of interest for behavioral economists studying less-than-fully-rational decision making. Libby Jenke and Michael Munger provide an interesting experiment in "Attention Distribution as a Measure of Issue Salience". Jenke and Munger emphasize that candidates take positions on numerous issues. Not all issue dimensions, though, are salient to voters. The question becomes, what determines the issues to which voters devote their attentions? The difficult empirical problem is how to measure attention. The authors provide a novel mechanism of "mouse tracking" to identify the on-screen icons over which subjects hover their mouses in searching for information online. Time spent reading the information provided is a useful measure of attention.

The experiment asks subjects to evaluate hypothetical candidates running for elected office. The method creates a measure of the topics to which subjects pay attention when making political decisions. Thus, it relates to the "rationally irrational" literature in public choice wherein people are viewed as choosing how much (costly) effort to expend on the quality of their political choices (Caplan, 2007; McCannon \& Walker, 2016, 2020).

Limited attention is a potential explanation for the empirical results presented by Anna Harvey and Taylor Mattia in "Does Money Have a Conservative Bias?". It has long been recognized that campaign spending influences election outcomes, which is not obvious in a world of individuals having clear policy preferences. Harvey and Mattia explore the Citizens United Supreme Court decision, which lifted some restrictions on political campaign contributions. They ask whether changes in the sources of campaign finance influences votes cast. They provide evidence that the ruling lead to increased conservatism, which they interpret as being driven by changes in preferences. Spending on campaign advertisements either influences policy votes directly through their assessments of the policy's impact, or through providing information on social norms.

\section{Social norms}

Social norms represent an important area for future public choice scholarship. In "Nudging with Care: The Risks and Benefits of Social Information", Cristina Bicchieri and Eugen Dimant begin by offering a definition of social norms. To them, a "norm is a behavioral rule which prescribes or proscribes a certain behavior to a specific group of people in a 
specific class of situations." A social norm exists when enough others follow it and believe that members of the group expect others should follow it and, moreover, may be willing to penalize deviations to enforce it.

In other words, research on social norms combines explorations of preferences with evaluations of the behavioral effects of information and beliefs. If people hold contingent cooperating preferences, they will follow a social norm if they believe enough others are doing so as well. Deviating from the anticipated norm of behavior generates a disutility. Thus, expectations enter directly into the objective function. Such individuals are contingent cooperators, rather than fully pro-social actors. Expectations play a central role in cooperative behavior. ${ }^{4}$

For public policy applications, one way that norms can be influenced is by "nudging" choices. Coined by Thaler and Sunstein (2008), a nudge is "any aspect of the choice architecture that alters people's behavior in a predictable way without forbidding any options or significantly changing their economic incentives." Informational nudges in field experiments have exploded. In fact, the UK's so-called Behavioural Insights Team actively develops such interventions to inform government agencies. ${ }^{5}$ In "Efficiency Criteria for Nudges and Norms", Kip Viscusi outlines a cost-benefit criteria for nudges. Nudges are substantially less intrusive than coercive mandates (e.g., selective taxes or subsidies). He points out, though, that policies adopting financial incentives inherently are zero-sum. Nudges, on the other hand, will involve some resource costs. Hence, financial incentives can be viewed as having a cost advantage.

A prevalent example of social norms is group "identity". Peter Boettke and Henry Thompson discuss the public choice implications of identity in "Identity and Off-Diagonals". They build on James Buchanan's (1978) notion of an artifactual man. For him, a person's character is determined by choices made over time. By identifying with particular groups, Boettke and Thompson argue that identity raises the costs of political cooperation, exacerbates wasteful rent-seeking, and potentially leads to defection/tribal violence. Group identities, of course, remove methodological individualism from the analytical picture.

\section{Conclusion}

The articles included in this special issue are just a sample of some of the ways in which insights gained from behavioral economics can contribute to public choice research. The examples of research exploring pro-social preferences, less-than-fully-rational decision making, and the influence of social norms contained herein are just the tip of the proverbial iceberg. Our hope is twofold. First, we believe that exposing public choice scholars to findings in behavioral economics may spur researchers to think about how the former can inform the latter. Second, public choice has a respectable history of influencing other subfields of economics and political science by demanding that investigators consider seriously the incentives and motivations of public-sector actors. Behavioral economics, for the most part, has focused on the choices made by the population at large. The ways in which public actors themselves may be influenced by behavioral biases have for the most part been overlooked. For example, Chen et al. (2016) show that judges may be subject to

\footnotetext{
${ }^{4}$ See DeAngelo and McCannon (2020) for a suggested formal modeling approach.

5 www.bi.team
} 
the gambler's fallacy whereby negative serial correlation in decisions is detected. How the intricacies of human behavior may distort regulators, politicians, voters, or bureaucrats' decision making may very well be an important future line of research.

A word of caution is warranted. Behavioral economics is a positive science that collects information from observational data and controlled experiments to test hypotheses about human behavior. It is quite easy to slip into a normative analysis of policies. ${ }^{6}$ For example, if individuals are inherently norm compliers, can informational nudges be used to make their lives better? The answer is controversial because it requires that we take a stance on what makes one's life better. Richard Thaler views interventions that help people make decisions that they would have wanted to make as "libertarian paternalism" (Thaler \& Sunstein, 2003). Opponents criticize that approach on a number of grounds. Prominently, if policymakers presume that individual preferences are coherent, then they are left to assign primacy to their own conceptions of well-being (Sugden, 2009). Using behavioral economics to improve our understanding of how institutions affect people's decisions, without letting the field be a tool to be used by special interest groups as cover for their preferred policies, is the trick for future research and applications.

\section{References}

Bicchieri, C., \& Dimant, E. (2019). Nudging with care: The risks and benefits of social information. Public Choice, forthcoming. https://doi.org/10.1007/s11127-019-00684-6.

Boettke, P. J., \& Thompson, H. A. (2019). Identity and off-diagonals: How permanent winning coalitions destroy democratic governance. Public Choice, forthcoming. https://doi.org/10.1007/ s11127-019-00683-7.

Botelho, A., Harrison, G. W., Costa Pinto, L. M., Ross, D., \& Ruström, E. E. (2021). Endogenous choice of institutional punishment mechanisms to promote social cooperation. Public Choice, forthcoming. https://doi.org/10.1007/s11127-020-00868-5.

Buchanan, J. M. (1978). Natural and artifactual man. In J. Buchanan (Ed.), The collected works of James M. Buchanan, Vol. I: The logical foundations of constitutional liberty. Indianapolis: Liberty Fund.

Buchanan, J. M., \& Tullock, G. (1962). The calculus of consent: Logical foundations of constitutional democracy. University of Michigan Press.

Caplan, B. (2007). The myth of the rational voter: Why democracies choose bad policies. Princeton University Press.

Chen, D. L., Moskowitz, T. J., \& Shue, K. (2016). Decision making under the gambler's fallacy: Evidence from asylum judges, loan officers, and baseball umpires. Quarterly Journal of Economics, 131(3), 1181-1242.

Congleton, R. (2019). Behavioral economics and the Virginia school of political economy: Overlaps and complementarities. Public Choice, forthcoming. https://doi.org/10.1007/s11127-019-00679-3.

DeAngelo, G. J., Dubois, D., \& Romaniuc, R. (2020). The perils of democracy. Journal of Economic Behavior \& Organization, 175, 328-340.

DeAngelo, G., \& McCannon, B. C. (2020). Psychological game theory in public choice. Public Choice, 182(1-2), 159-180.

Fehr, E., \& Gächter, S. (2000). Cooperation and punishment in public goods experiments. American Economic Review, 90(4), 980-994.

Fehr, E., \& Gächter, S. (2002). Altruistic punishment in humans. Nature, 415, 137-140.

Harvey, A., \& Mattia, T. (2019). Does money have a conservative bias? Estimating the causal impact of Citizens United on state legislative preferences. Public Choice, forthcoming. https://doi.org/10.1007/ s11127-019-00721-4.

\footnotetext{
${ }^{6}$ See McChesney (2013) for a further discussion on this point.
} 
Hassan, M., Mansour, S., Voigt, S., \& Gadallah, M. (2019). When Syria was in Egypt's land: Egyptians cooperate with Syrians, but less with each other. Public Choice, forthcoming. https://doi.org/10.1007/ s11127-019-00727-y.

Heath, J. (2020). Methodological individualism. In E. N. Zalta (Ed.), The Stanford encyclopedia of philosophy. Metaphysics Research Lab, Stanford University.

Isaac, R. M., \& Norton, D. (2013). Endogenous institutions and the possibility of reverse crowding out. Public Choice, 156, 253-284.

Jenke, L., \& Munger, M. (2019). Attention distribution as a measure of issue salience. Public Choice, forthcoming. https://doi.org/10.1007/s11127-019-00711-6.

Kahneman, D. (2011). Thinking fast and slow. Penguin.

Lefgren, L. F., Sims, D. P., \& Stoddard, O. B. (2016). Effort, luck, and voting for redistribution. Journal of Public Economics, 143, 89-97.

McCannon, B. C., \& Walker, P. (2016). Endogenous competence and a limit to the Condorcet Jury Theorem. Public Choice, 169(1), 1-18.

McCannon, B. C., \& Walker, P. (2020). Individual competence and committee decision making: Experimental evidence. Southern Economic Journal, 86(4), 1531-1558.

McChesney, F. S. (2013). Behavioral economics: Old wine in irrelevant new bottles? Supreme Court Economic Review, 21, 43-76.

Mollerstrom, J. (2019). Favoritism and cooperation. Public Choice, forthcoming. https://doi.org/10.1007/ s11127-019-00716-1.

Morton, R. B., Ou, K., \& Qin, X. (2020). Analytical thinking, prosocial voting, and intergroup competition: Experimental evidence from China. Public Choice, forthcoming. https://doi.org/10.1007/ s11127-020-00859-6.

Olson, M. (1965). The logic of collective action: Public goods and the theory of groups. Harvard University Press.

Ostrom, E., Walker, J., \& Gardner, R. (1992). Covenants with and without a sword: Self-governance is possible. American Journal of Political Science, 86(2), 404-417.

Sugden, R. (2009). On nudging. Journal of Economics and Business, 16(3), 365-373.

Thaler, R. (2018). From Cashews to Nudges: The evolution of behavioral economics. American Economic Review, 108(6), 1265-1287.

Thaler, R. H., \& Sunstein, C. R. (2003). Libertarian paternalism. American Economic Review, 93(2), 175-179.

Thaler, R. H., \& Sunstein, C. R. (2008). Nudge: Improving decisions about health, wealth, and happiness. Penguin.

Tullock, G. (1971). Public decisions as public goods. Journal of Political Economy, 79(4), 913-918.

Viscusi, K. (2019). Efficiency criteria for nudges and norms. Public Choice, Forthcoming. https://doi.org/ $10.1007 / \mathrm{s} 11127-019-00712-5$

Publisher's Note Springer Nature remains neutral with regard to jurisdictional claims in published maps and institutional affiliations. 